\title{
ASSOCIATION OF MIGRAINE SEVERITY AND DISABILITY WITH BODY MASS INDEX.
}

1. MBBS, M.Phil (Physiology) Assistant Professor Physiology Indus Medical College, Tando Muhammad Khan, Sindh. 2. MBBS, MD (General Medicine) Assistant Professor Medicine Indus Medical College, Tando Muhammad Khan, Sindh.

3. MBBS, M.Phil Anatomy Associate Professor Anatomy Liaquat University of Medical and Health Sciences Jamshoro.

4. MBBS, M.Phil (Physiology) Professor Physiology Indus Medical College, Tando Muhammad Khan, Sindh.

Correspondence Address:

Dr. Kavita Bai

Department of Physiology

Indus Medical College,

Tando Muhammad Khan, Sindh,

Pakistan.

baidrkavita@gmail.com

Article received on:

05/08/2019

Accepted for publication:

$16 / 12 / 2019$

\begin{abstract}
Kavita Bai ${ }^{1}$, Ramesh Kumar Suthar ${ }^{2}$, Pushpa Goswami ${ }^{3}$, Mumtaz Ali Memon ${ }^{4}$
\end{abstract}
\begin{abstract}
Objectives: To explore the association of migraine severity and disability with body mass index. Study Design: Cross sectional study. Setting: Department of Medicine and Physiology of Indus Medical College, Tando Muhammad Khan. Period: August 2018 and March 2019. Material \& Methods: It included all patients both female and male diagnosed with migraine of age group 18-55 years. Diagnosis of migraine was done according to the guidelines by international headache society. Patients were divided into four groups according to various body mass index categories as per the revised guidelines into underweight: m2, Overweight: $23.0-24.9 \mathrm{~kg} / \mathrm{m} 2$, Obesity: $>25 \mathrm{~kg} / \mathrm{m} 2$. Clinical features of migraine were compared in these groups. The collected data was analyzed in SPSS version 18.00. Results: A total $189(n=189)$ participants recruited in this study, meeting selection criteria were included. Out of 189,73 presented with aura while 116 presented without aura. So the study population divided into two groups one wit aura $(n=73)$ and other without aura $(n=116)$. Mean \pm SD of MIDAS score, waist hip ratio, age of onset of headache (in years), frequency of headache per month and the duration of headache (in hours), of the study participants were $12.18 \pm 4.48,0.87 \pm .066,18.89 \pm 2.97,10.93 \pm 2.70$ and $67.32 \pm 12.52$ respectively. Out of 189 migraine patients $(n=189), 30(15.87 \%)$ were with normal BMI, 11(5.82\%) were underweight, $111(58.73 \%)$ were overweight and remaining $37(19.58 \%)$ were obese. Similarly, when mean \pm SD of the duration of headache (in hours) compared among normal BMI $(n=30)$, underweight $(n=11)$, overweight $(n=111)$ and obese $(\mathrm{n}=37)$, it was $66.06 \pm 10.70,58.9091 \pm 15.62,66.64 \pm 9.01$ and $72.86 \pm 18.82$ respectively. ( $p$ value 0.004 and $f$ value 4.52) that is statistically significant. Conclusion: This study demonstrates that there is strong positive association between the severity and disability due to migraine with increase in body nass index. Future research is required to fill the gap to explore the pathophysiologic mechanisms beside this association.
\end{abstract}

Key words: $\quad$ Body Mass Index, Migraine, With Aura, Without Aura.

Article Citation: Bai K, Suthar RK, Goswami P, Memon MA. Association of migraine severity and disability with body mass index. Professional Med J 2020; 27(5):979986. DOI: 10.29309/TPMJ/2020.27.05.4012

\section{INTRODUCTION}

Migraine is a complex besides multifaceted neurological illness comprising of events of head pain usually throbbing, one-sided and severe. ${ }^{1,2}$ which may last over several days. It is seventh leading cause of disability affecting the quality of life for many years, may impact on economy of patient because of inability to perform daily activities / work. Nearly $15 \%$ of the population worldwide is suffering from this annoying issue. Patient with migraine experiences headache for a long time with recurrent migraine attacks regardless of enhanced acute and prophylactic treatments. ${ }^{3}$ According to the International Headache Society (IHS) ${ }^{4}$, migraines attacks usually last four to seventy two hours, commonly related with nausea, vomiting, photophobia,sensitivity to sound, or movement. Almost one-third of migraine patients have attacks that are preceded or accompanied by an aura. Aura is defined as characteristic transient focal neurological symptoms, visual in most instances, sensory, speech and motor function disabilities may also be encountered. ${ }^{1}$ Cross sectional nationwide prevalence survey, reports prevalence of headache among Pakistani population is $76.6 \%$, and of migraine was $22.5 \% .^{5}$

According to the World Health Organization, migraine is ranked $20^{\text {th }}$ in the world's debilitating disorder, and the resulting burden from migraine alone surpasses the burden of stroke, epilepsy ,multiple sclerosis, Alzheimer's disease and Parkinsons Disease. ${ }^{6}$ Migraine as well as obesity are two foremost issues of well-being concern, substantially affecting the quality of life physically, mentally and economically. Pakistan is the 9th most obese nation in the world. ${ }^{7,8}$ Previous studies had revealed that obese 
migraine patients had frequent, severe attacks of migraine with raised associated symptoms such as advanced disability grades, aura and an increased frequency of sensitivity to light and sensitivity to sound. ${ }^{9}$ The association among obesity and migraine is the attention of current clinical research. ${ }^{9,10}$ Migraine has been classically divided into four phases: the premonitory, aura, headache, and postdrome phases. ${ }^{2}$ Studies conducted for on pathophysiology of migraine revealed that non-obese female migraineurs suffer from hyperinsulinemia, which is associated with elevated leptin and (glucagon like peptide) GLP-2 levels. Increased leptin and GLP-2 are risk factors for migraine. Neurotransmitter serotonin related abnormalties have been suggested as a neurochemical basis for migraine. ${ }^{11}$ Migraine disability assessment questionnaire MIDAS was established to evaluate headache-associated disability with the purpose of improving migraine related care. It is a self-administered questionnaire designed to quantify headache-related disability over a three-month period. ${ }^{12,13}$

This questionnaire consists of five questions that focus on time or productivity lost, as well as the limited ability to participate in work or school, domestic doings and family, and social or leisurely activities. The total MIDAS score can be used to define four grades of migraine-related disability. Grade 1 for "little or no disability" (0-5); Grade 2 for "mild disability" (6-10); Grade 3 for "moderate disability" (11-20); Grade 4 for "severe disability" $(\geq 21) .^{12}$

The rationale of this study is to explore the association of migraine severity and disability with body mass index. It is hypothesized that severity of migraine and related disability are directly related to the changes in body mass index. BMl determined according to the World Health Organization classification as "underweight" (<18.5), "normal" (18.5-24.9), "overweight" (25.0-29.9), "obese" (30-39.9) or "morbidly obese" (>40).

\section{MATERIAL \& METHODS}

All the volunteers of age group 18 to 45 years of either gender diagnosed with migraine included in this study.

High blood pressure, diabetes mellitus any other neurovascular condition that cause headache excluded from the study.

This cross sectional research study was done in the Department of Medicine and Physiology of Indus Medical College, Tando Muhammad Khan, from August 2018 and March 2019. It included all patients both female and male diagnosed with migraine of age group 18-55 years. Diagnosis of migraine was done according to the guidelines by international headache society. Patients with any other type of headache, neurological or psychiatric comorbidities, high blood pressure, and diabetes mellitus were not included in the study. This study was approved by the ethical committee of the Institute. Informed written consent was taken from all participants before clinical interview and measurements. Demographic variables were recorded on predesigned proforma, and then structured interview was conducted. Particulars of Migraine history such as age of onset of headache in years, frequency of headache per month, history of presence of aura, duration of headache in hours, severity \& disability due to disease followed by clinical neurological examination. Severity of migraine was evaluated according to MIDAS survey questionnaire, which is used to assess the actual impact of headache in last three months on patient's quality of life, influence of migraine on daily life was assessed using the Migraine Disability Assessment Scale (MIDAS) questionnaire.

Obesity was determined from Body mass index, which was calculated as weight in kilograms divided by the square of height in meters $(\mathrm{kg} / \mathrm{m} 2)$. Patients were divided into four groups according to various body mass index categories as per the revised guidelines into underweight: $\mathrm{m} 2$, Overweight: $23.0-24.9$ kg/m2, Obesity: > 25 kg/ $\mathrm{m} 2$. Clinical features of migraine were compared in these groups.

\section{RESULTS}

A total $189(n=189)$ participants recruited in this study, meeting selection criteria were included. 
Out of 189, 73 presented with aura while 116 presented without aura.So the study population divided into two groups one wit aura $(n=73)$ and other without aura $(n=116)$. The overall mean age + SD (range) was $28.80+8.54(18$ to 48 years). There was no significant difference of age (compare means) between male and ladies subjects $(p$ value $=0.99)$. Table-l

The study participants $(n=189)$ divided into two types, first migraine with Aura $n=73(38.62 \%)$ and second Migraine without aura $n=116$ (61.36\%). Figure-1

Mean \pm SD of MIDAS score, waist hip ratio, age of onset of headache (in years), frequency of headache per month and the duration of headache (in hours), of the study participants were $12.18+4.48,0.87+.066,18.89+2.97,10.93+2.70$ and $67.32+12.52$ respectively. Table-I

Mean \pm SD of MIDAS Score among the miranieuers without aura $(n=116)$ was $12.18 \pm 4.48$ but among the patients who presented with aura $(n=73)$, it was $16.39 \pm 6.39$. ( $P$ value $<0.01)$ that presents statistically significant association of the type of migraine with MIDAS score. Table-III

Out of 189 migraine patients $(n=189)$, $30(15.87 \%)$ were with normal BMI, 11(5.82\%) were underweight, $111(58.73 \%)$ were overweight and remaining $37(19.58 \%)$ were obese. Figure-2

Mean of the MIDAS score among normal BMI $(n=30)$, underweight $(n=11)$, overweight $(n=111)$ and obese $(n=37)$, when compared by applying ANOVA test; MIDAS score among these four groups were 11.43, 11.18, 10.81 and 17.18 respectively. (f value 27.3 and $p$ value 0.001 ). That reveals the significant disability and disturbed quality of life among the migraineurs who are overweight and obese. Table-IV

Similarly, when mean $\pm S D$ of the duration of headache (in hours) compared among normal BMI $(n=30)$, underweight $(n=11)$, overweight $(n=111)$ and obese $(n=37)$, it was $66.06 \pm 10.70$, $58.9091 \pm 15.62,66.64 \pm 9.01$ and $72.86 \pm 18.82$ respectively. ( $p$ value 0.004 and $f$ value 4.52 ) that is statistically significant. Duration of headache was more among obese migraine patients. TableIV

When Body mass index evaluated according to type of migraine, among the migraine patients without aura $(n=116), 18(60 \%)$ were of normal $\mathrm{BMI}, 8(72.7 \%)$ of underweight BMI, $89(80.2 \%)$ were overweight and 1 (2.7\%) was obese. Instead, among the migraine patients with aura, 12(40.0\%) were of normal BMI, $3(27.3 \%)$ of underweight, $22(19.8 \%)$ were overweight and $36(97.3 \%)$ were obese. $\mathrm{P}$ value $<0.001$ with Pearson chi aquare value $70.910^{a}$ Table-V.

When MIDAS grade compared among the patients with aura $(n=116)$ and without aura $(n=37)$ there was significant difference of MIDAS grade between these two groups. ( $p$ value 0.005 ) Table-VI.

Waist hip ratio was more among the patients of migraine with aura when matched with the patients without aura. ( $P$ value $<0.01$ ) Table-VII.

\begin{tabular}{|c|c|c|c|c|c|}
\hline & $\mathbf{N}$ & Minimum & Maximum & Mean & Std. Deviation \\
\hline Waist hip ratio & 189 & .79 & 1.06 & .8711 & .06675 \\
\hline Age of onset of headache (in years) & 189 & 14.00 & 25.00 & 18.8995 & 2.97068 \\
\hline Duration of headache (in hours) & 189 & 36.00 & 144.00 & 67.3228 & 12.52005 \\
\hline
\end{tabular}




\begin{tabular}{|l|l|c|c|c|c|c|}
\hline & Gender & N & Mean & $\begin{array}{c}\text { Std. } \\
\text { Deviation }\end{array}$ & $\begin{array}{c}\text { Std. Error } \\
\text { Mean }\end{array}$ \\
\hline \multirow{2}{*}{ Age (in years) } & Male & 62 & 29.0484 & 8.52850 & 1.08312 \\
\cline { 2 - 6 } & Female & 127 & 28.6850 & 8.58450 & .76175 & 0.99 \\
\hline
\end{tabular}

Table-II. Gender based distribution of study population $(n=189)$

\begin{tabular}{|c|c|c|c|c|c|c|}
\hline & $\begin{array}{l}\text { Type of } \\
\text { Migraine }\end{array}$ & $\mathbf{N}$ & Mean & Std. Deviation & $\begin{array}{l}\text { Std. Error } \\
\text { Mean }\end{array}$ & P-Value \\
\hline \multirow{2}{*}{ MIDAS Score } & Without aura & 116 & 9.5345 & 2.44391 & .22691 & \multirow{2}{*}{$<0.01 * *$} \\
\hline & With aura & 73 & 16.3973 & 3.69587 & .43257 & \\
\hline
\end{tabular}

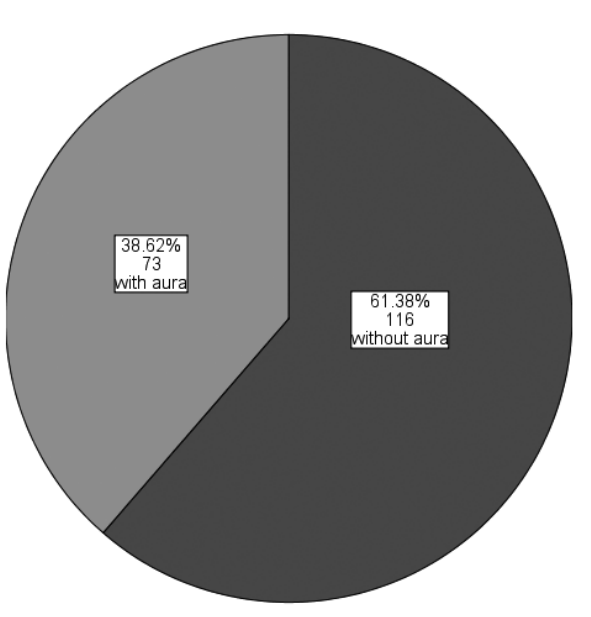

Figure-1. Frequency of type of migraine

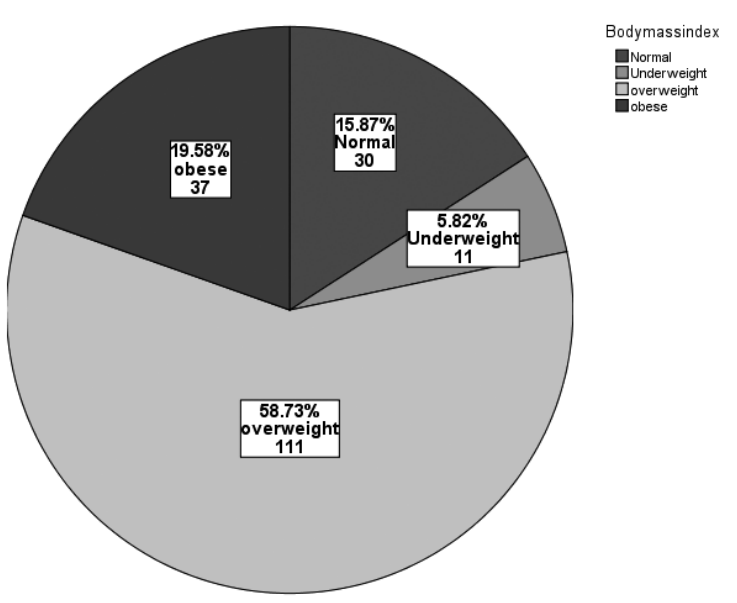

Figure-2. BMI based distribution of migraneuers $(n=189)$

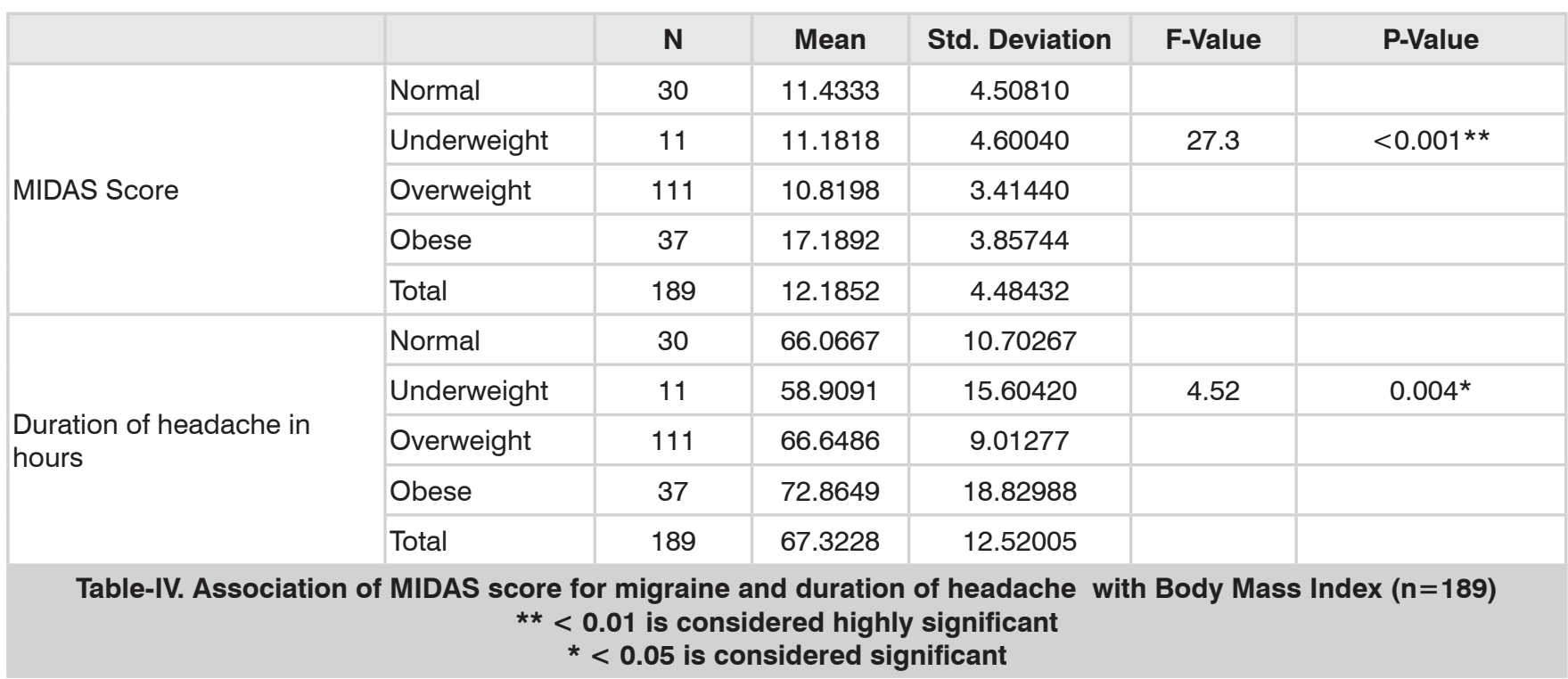




\begin{tabular}{|c|c|c|c|c|c|c|}
\hline \multirow[t]{2}{*}{ Type of Migraine } & \multicolumn{4}{|c|}{ Body mass index } & \multirow[b]{2}{*}{ Total } & \multirow[b]{2}{*}{ P-Value } \\
\hline & Normal & Underweight & overweight & obese & & \\
\hline without aura & 18 & 8 & 89 & 1 & 116 & \\
\hline \multirow{2}{*}{ with aura } & 12 & 3 & 22 & 36 & 73 & $<0.001^{* *}$ \\
\hline & $40.0 \%$ & $27.3 \%$ & $19.8 \%$ & $97.3 \%$ & $38.6 \%$ & \\
\hline Total & $100.0 \%$ & $100.0 \%$ & $100.0 \%$ & $100.0 \%$ & $100.0 \%$ & \\
\hline \multicolumn{6}{|c|}{$\begin{array}{l}\text { Table-V. Type of migraine and body mass index cross tabulation Pearson chisquare } \\
\star \star * ~ p \text { value }<0.01 \text { is considered highly significant }\end{array}$} & $10^{a}$ \\
\hline
\end{tabular}

\begin{tabular}{|c|c|c|c|c|c|c|}
\hline \multirow[t]{2}{*}{ Count } & & \multicolumn{4}{|c|}{ MIDAS grade } & \multirow{2}{*}{ Tota } \\
\hline & & Grade I & Grade II & Grade III & Grade IV & \\
\hline Type of migraine & without aura & 4 & 79 & 33 & 0 & 116 \\
\hline \multicolumn{2}{|l|}{ Total } & 4 & 80 & 81 & 24 & 189 \\
\hline \multicolumn{7}{|c|}{$\begin{array}{l}\text { Table-VI. Association of migraine with MIDAS grade }(n=189) \\
\text { Pearson chi square value }=1.023 E 2 a \\
\text { P value }<0.001\end{array}$} \\
\hline
\end{tabular}

\begin{tabular}{|c|c|c|c|c|c|}
\hline & Type of migraine & $\mathbf{N}$ & Mean & Std. Deviation & Std. Error Mean \\
\hline \multirow[t]{2}{*}{ Waist hip ratio } & without aura & 116 & .8705 & .07005 & .00650 \\
\hline & with aura & 73 & .8721 & .06160 & .00721 \\
\hline
\end{tabular}

\section{DISCUSSION}

Primary headache and obesity are vastly widespread ailments in the general populace. While many research studies have revealed an association between the primary headache and obesity, there is still no overall comprehension about this link. To achieve a more perfect understanding in this favor, this research study has been accompanied.

Mean age of migraine sufferers in several research studies was 33 years while in this research study it is 18 to 48 years. Mean age of subjects was $34.5 \pm 7.4$ years and $77.9 \%$ of them were ladies. ${ }^{14}$ According to this research study, migraine is more prevalent in females as compared to males; this finding is supported by cupini LM et al. and his colleagues by concluding in their research that gonadal hormone fluctuation may impact both forms of migraine ${ }^{15}$ Migraine headaches are three times more prevalent in ladies than in men. ${ }^{16}$ According to Thierrr $A$ et al, 66 migraineurs, more than half $37(56.06 \%)$ had a migraine with aura but according to this research study $73(63 \%)$ presented with aura out of 189 migraine patients. ${ }^{17}$ Mean \pm SD waist hip ratio in this study is $0.87+.066$, that is analogous to a research study published in the Iranian journal of Neurology, also showed mean waist hip ratio in migraineuers as $0.86 .{ }^{18}$

According to this research study, waist hip ratio was raised among the patients of migraine with aura when matched with the patients without aura. ( $P$ value $<0.01$ ) and according to Laino $D$ etal., a decrease in body weight cause decrease in the incidence and severity of headache and my also represent an key therapeutic strategy. ${ }^{19,20}$

In this research study, out of 189 migraine patients $(n=189), 30(15.87 \%)$ were with normal body mass index, $11(5.82 \%)$ were underweight, $111(58.73 \%)$ were overweight and remaining $37(19.58 \%)$ were obese. So that most of the migraine patients were overweight. When mean $\pm S D$ of the duration of headache (in 
hours) compared among normal body mass index $(n=30)$, underweight $(n=11)$, overweight $(n=111)$ and obese $(n=37)$, it was $66.06 \pm 10.70$, $58.9091 \pm 15.62, \quad 66.64 \pm 9.01$ and $72.86 \pm 18.82$ respectively. ( $p$ value 0.004 and $f$ value 4.52 ) that is statistically significant. Duration of headache was more among obese migraine patients. When Body mass index evaluated according to type of migraine, among the migraine patients without aura $(n=116), 18(60 \%)$ were of normal body mass index, $8(72.7 \%)$ of underweight body mass index, 89(80.2\%) were overweight and 1 (2.7\%) was obese. Instead, among the migraine patients with aura, $12(40.0 \%)$ were of normal body mass index, $3(27.3 \%)$ of underweight, $22(19.8 \%)$ were overweight and 36(97.3\%) were obese. $P$ value $<0.001$ with Pearson chi aquare value 70.910a. These outcomes are similar to that of Thierrr A et al. ${ }^{17}$ who found a significant association between migraine and body mass index with a $p$ value at 0.0019 . There were more migraine sufferers among obese subjects 24 (36.36\%) and overweight subjects 23 (34.85\%) and the risk of migraine increases with body mass index. There is increased frequency, severity of migraine and aura, which is obvious by brief focal neurological symptoms frequently preceding or often accompanying the headache, is found to occur more in obese migraine patient. ${ }^{21}$ One research study found low severity scores in patients with normal body mass index, which increased with increasing body mass index. ${ }^{22}$

Miri A et al ${ }^{14}$ observed that obesity is absolutely positively linked with risk of migraine with aura. In addition, subjects with obesity had higher headache daily result matched with those with normal weight. Mean \pm SD of MIDAS Score among the migraine sufferers without aura $(n=116)$ was $12.18 \pm 4.48$ but among the patients who presented with aura $(n=73)$, it was $16.39 \pm 6.39$. ( $P$ value $<0.01)$ that presents statistically significant association of the type of migraine with MIDAS score. In several research studies, it has been revealed that MIDAS score is less in normal body mass index subjects as compared to obese people, our findings are consistent with such research studies that MIDAS score is raised in obese persons and overweight people as compared to normal and underweight body mass index populce. ${ }^{21,22}$ Mean of the MIDAS score among normal body mass index, underweight, overweight and obese, when compared by applying ANOVA test; MIDAS score among these four groups were 11.43, 11.18, 10.81 and 17.18 respectively. (f value 27.3 and $p$ value 0.001 . That shows the significant disability and troubled quality of life among the migraine sufferers who are overweight and obese.

Tiu DN et al. ${ }^{16}$ observed that maximum MIDAS score was present in obese patients (19.6) while it was lowest in normal subjects. The difference was significant $(P<0.05)$. When MIDAS grade compared among the patients with aura $(n=116)$ and without aura $(n=37)$ there was significant difference of MIDAS grade between these two groups. ( $p$ value 0.005); Tiu DN et al. ${ }^{16}$ also revealed that the proportion of subjects with severe headache pain increased with body mass index, doubling in the morbidly obese relative to the normally weighted. Similar significant associations were demonstrated with body mass index category for disability, photophobia, and phonophobia. Obesity and its related complications, such as insulin-resistance, are risk agents for chronic migraine: this is highlighted by the evidence that an improvement of metabolic control in obese subjects, through body mass index correction, may reduce frequency of migraine attacks. The relationship between obesity and migraine is multifaceted and comprises both central and peripheral pathways, but obesity and migraine are also both influenced by sedentary ways of life factors. ${ }^{20}$

\section{CONCLUSION}

Migraine and its severity are positively associated with body weight (revealed by Body Mass Index) and abdominal obesity (revealed by waist hip ratio). Further the area is open for further research to understand the pathophysiological mechanisms beside increased frequency of migraine among obese people and how loss in weight improves migraine symptoms.

\section{Copyright $@ 16$ Dec, 2019.}




\section{REFERENCES}

1. Bond DS, Roth J, Nash JM, Wing RR. Migraine and obesity: Epidemiology, possible mechanisms and the potential role of weight loss treatment. Obes Rev. 2011; 12(5):e362-e371.

2. Goadsby PJ, Holland PR, Martins-Oliveira M, Hoffmann $\mathrm{J}$, Schankin C, Akerman S. Pathophysiology of Migraine: A Disorder of Sensory Processing. Physiol Rev. 2017; 97(2):553-622. doi:10.1152/physrev.00034. 2015.

3. Herd CP, Tomlinson CL, Rick C, Scotton WJ, Edwards J, Ives NJ, Clarke CE, Sinclair AJ. Cochrane systematic review and meta-analysis of botulinum toxin for the prevention of migraine. BMJ Open. 2019 Jul 1; 9(7):e027953.

4. Headache Classification Committee of the International Headache Society (IHS). The international classification of headache disorders, 3rd edition (beta version). Cephalalgia 2013; 33:629-808.

5. Herekar AA, Ahmad A, Uqaili UL, et al. Primary headache disorders in the adult general population of Pakistan - A cross sectional nationwide prevalence survey. J Headache Pain. 2017; 18(1):28. doi:10.1186/ s10194-017-0734-1.

6. WHO, Lifting the burden. Atlas of headache disorders and resources in the world 2011. ISBN: 9789241564212.

7. Maira Siddiqui, Hareem Ayub, Rabia Hameed, Atif Amin Baig, et al. Obesity in Pakistan; Current and Future Perceptions. Curr Trends Biomedical Eng \& Biosci. 2018; 17(2): 555958. DOI: 10.19080/ CTBEB.2018.17.555958.

8. M. Naeem, S. Durr-E-Nayab, and M. Khalid. Prevalence and determinants of overweight and obesity among adults in Pakistan. [Feb; 2019];. https://pide.org.pk/ $\mathrm{pdf} / \mathrm{cphsp} / \mathrm{PIDE}-\mathrm{CPHSP}-2$.pdf Institute of development economics Health and Economic Consequences of Overweight and Obesity Among Adults. 2015.

9. Huang Q, Liang X, Wang S, Mu X. Association between body mass index and migraine: A Survey of Adult Population in China. BehavNeurol. 2018;2018:6585734. Published 2018 Apr 19. doi:10.1155/2018/6585734.

10. Winter AC, Berger K, Buring JE, Kurth T. Body mass index, migraine, migraine frequency and migraine features in women. Cephalalgia. 2009; 29(2):269-278. doi:10.1111/j.1468-2982.2008.01716.x.
11. Bernecker C, Pailer S, Kieslinger P, Horejsi R, et al. GLP2 and leptin are associated with hyperinsulinemia in non-obese female migraineurs. Cephalalgia. 2010 Nov; 30(11):1366-74. doi: 10.1177/0333102410364674. Epub 2010 Mar 26.

12. Sajobi TT, Amoozegar F, Wang M, Wiebe N, Fiest KM, Patten SB, Jette N. Global assessment of migraine severity measure: Preliminary evidence of construct validity. BMC neurology. 2019 Dec; 19(1):53.

13. Stewart WF, Lipton RB, Kolodner KB, Sawyer J, Lee $\mathrm{C}$, Liberman JN. Validity of the Migraine Disability Assessment (MIDAS) score in comparison to a diarybased measure in a population sample of migraine sufferers. Pain. 2000 Oct 1; 88(1):41-52.

14. Miri A, Nasiri M, Zonoori S, Yarahmad F, DabbaghMoghadam A, Askari G, Sadeghi O, Asadi M. The association between obesity and migraine in a population of Iranian adults: A case-control study. Diabetes \& Metabolic Syndrome: Clinical Research \& Reviews. 2018 Sep 1; 12(5):733-6.

15. Cupini LM, Matteis M, Troisi E, Calabresi P, Bernardi G, Silvestrini M. Sex $\square$ hormone $\square$ related events in migrainous females. A clinical comparative study between migraine with aura and migraine without aura. Cephalalgia. $1995 \mathrm{Apr} ;$ 15(2):140-4.

16. Tiu DN, Das D. Assessment of relation of migraine \& obesity in study population. J Adv Med Dent Scie Res 2019; 7(2):84-86.

17. Thierry A, Mendinatou A, Aude G, Bohr SC, Dismand $\mathrm{H}$. Migraine and obesity in parakou in 2017: CaseControl Study. Pain Studies and Treatment. $2018 \mathrm{Jul}$ 30; 6(3):15-23.

18. Jahromi SR, Abolhasani M, Meysamie A, Togha M. The effect of body fat mass and fat free mass on migraine headache. Iran J Neurol. 2013; 12(1):23-7. PubMed PMID: 24250893; PubMed Central PMCID: PMC3829270.

19. Laino D, Vitaliti G, Parisi P, Pavone P, Verrotti A, Lubrano R, Matin N, Falsaperla R. Headache, migraine and obesity: An overview on plausible links. J Biol Regul Homeost Agents. 2016; 30:333-8.

20. Farello G, Ferrara P, Antenucci A, Basti C, Verrotti A. The link between obesity and migraine in childhood: A systematic review. Italian journal of pediatrics. 2017 Dec; 43(1):27.

21. Ojha P, Malhotra V, Pandey N. Association between generalized obesity and migraine features in Indian females. Indian J Physiol Pharmacol. 2018; 62(4):4537. 
22. Bigal ME, Tsang A, Loder E, Serrano D, Reed ML, Lipton RB (2007) Body mass index and episodic headaches: A population-based study. Arch Intern Med 167: 1964-1970.

\begin{tabular}{|c|c|c|c|}
\hline \multicolumn{4}{|c|}{ AUTHORSHIP AND CONTRIBUTION DECLARATION } \\
\hline Sr. \# & Author(s) Full Name & Contribution to the paper & Author(s) Signature \\
\hline 1 & Kavita Bai & $\begin{array}{l}\text { Concept, Statics and data } \\
\text { analysis. }\end{array}$ & \\
\hline 2 & Ramesh Kumar Suthar & Data collection. & \\
\hline 3 & Pushpa Goswami & Drafting and revision. & \\
\hline 4 & Mumtaz Ali Memon & $\begin{array}{l}\text { Critical revision and finalizing } \\
\text { of article. }\end{array}$ & \\
\hline
\end{tabular}

